\title{
Drive for Muscularity and Drive for Thinness: The Impact of Pro-Anorexia Websites
}

\author{
Lilia Juarez: McNair Scholar \\ Dr. Mary E. Pritchard: Mentor \\ Psychology
}

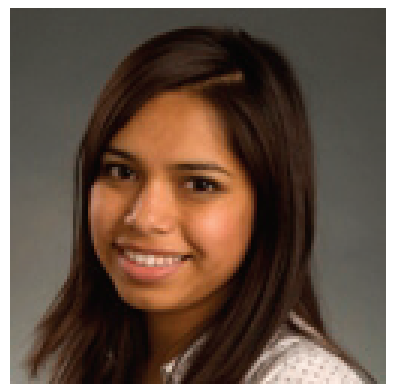

\begin{abstract}
In recent years, websites that stress the message of thinness as the ideal and only choice have surfaced on the internet. As a source of media, pro-anorexia websites have detrimental effects similar to other forms of media (e.g., magazines, TV). In addition, friends may be influencing one another to view these websites, thus increasing the risk of developing a drive for thinness in women and a drive for muscularity in men. Approximately 300 male and female undergraduate psychology students responded to questionnaires assessing: viewership and use of pro-anorexia websites, influence of friends to view pro-anorexia websites, drive for muscularity, and drive for thinness. Results showed viewership of pro-anorexia websites was positively correlated with drive for thinness in women, and negatively correlated with drive for muscularity in men. Pro-anorexia websites were found to be the only predictor of both drive for thinness in women and drive for muscularity in men.
\end{abstract}

\section{Introduction}

Disordered eating behaviors are occurring more frequently among adolescents and young adults (Tamim et al., 2006) and are now considered commonplace in Western society (Cook-Cottone \& Phelps, 2006). According to Weltzin et al. (2005), about 10\% of individuals with anorexia and bulimia are men, indicating that disordered eating behaviors can occur regardless of gender. Although anorexia and bulimia are more commonly recognized in our society, most individuals would fall under the category of Eating Disorder Not Otherwise Specified (EDNOS). The EDNOS category is for behaviors or disorders that do not necessarily meet the criteria for a diagnosis of anorexia or bulimia (APA, 2000); it includes anorexic-like and bulimic-like behaviors such as drive for thinness, excessive dieting, excessive exercising, purging and binging. Research shows that about $50 \%$ of adults that seek treatment for an eating disorder are diagnosed with EDNOS and $60 \%$ of most eating disorder cases are EDNOS (Fairburn et al., 2007; Fairburn \& Bohn, 2005). Drive for muscularity is a newly coined term, which is not yet classified under any specific disorder in the Diagnostic and Statistical Manual of Mental Disorders (DSM-V). However, Murray et al. (2010) argue that the drive for muscularity component in muscle dysmorphia is parallel to drive for thinness in anorexia because of the similarities of the symptoms and the high attention to diet, as well as the compensatory behavior of excessive exercise.

Regardless of classification, the onset of disordered eating behaviors and/or exercise behaviors can be attributed to a variety of factors; the influence of mass media is one contributor to increased drive for thinness in females (Rodgers, Paxton, \& Chabrol, 2010). Media ideals also increase the likelihood of drive for thinness in males (Leit, Gray, \& Pope, 2002). Alperin (2004 suggests high levels of disordered eating behaviors are due to media influence. Carney and Louw (2006) suggest that media consumption is frequently related to an increase in the occurrence of disordered eating behaviors and attitudes. According to Grabe, Ward, and Hyde (2008), media has an important role in defining female and male ideals. Due to the increased promotion of thin body ideals (Homan, 2010), eating disorders have been harder to prevent as adolescents have increased their media consumption.

Research has repeatedly found negative relationships between levels of media exposure and level of body satisfaction (Bardone-Cone \& Cass, 2007), even in men. Depiction of the ideal male body (as portrayed by the media) affects mood and body satisfaction in men (Agliata \& Tantleff-Dunn, 2004; Baird \& Grieve, 2006; Derenne, 2006). A study of undergraduate men also found that $9 \%$ to $12 \%$ of men were unhappy with their body and wanted to lose weight (O’Dea \& Abraham, 2002). Kjelsås, Bjørnstrøm, and Götestam (2004) suggest that media perpetuates and strengthens body perceptions and drive for thinness in young adults. Although thinness may not be the overall end goal for all men, pressure to conform to an ideal muscular body is similar to that of women's pressure to conform to the ideal thin body (Ridgeway \& Tylka, 2005). Leit et al. (2002) have suggested that one of the strongest 
predictors of drive for muscularity is the internalization of the media body ideals. Thus, while women tend to want to lose weight, men want to gain muscle weight.

Amongst various kinds of mass media, the internet has managed to embed itself as an increasing source of influence. In the past decade, pro-anorexia websites have surfaced. These websites contain images and writings that support the pursuit of an ideal thin body image (Williams \& Reid, 2007). Research has shown that pro-anorexia websites stress thinness as the ideal and only choice for women (Bardone-Cone \& Cass, 2006), and in some websites ideal images of muscularity and thinness for men. This latest form of mass media has been suggested as negative and detrimental to a female's eating behaviors and body image (Bardone-Cone \& Cass, 2007). According to Tiggemann and Miller (2010), internet media exposure has a direct effect on drive for thinness. Researchers found that women who had viewed these websites at least once had a decrease in self-esteem (Bardone-Cone \& Cass, 2007). Reports also show an increased likelihood of future engagement in many negative behaviors related to food, exercise, and weight (Bardone-Cone \& Cass, 2006). While research on pro-anorexia websites is still in its infancy, most research suggests that pro-anorexia websites affect college students negatively.

Although media sources are a strong influence, research suggests that adolescents rely greatly on their friends when it comes to the development of body image and weight-related behaviors (Wang, Houshyar, \& Prinstein, 2006). Shomaker and Furman $(2009,2010)$ found that interpersonal pressure from parents, romantic partners and friends are important sources of influence on attitudes or behaviors towards muscle gaining and on anorexic-like and bulimic-like behaviors such as drive for thinness, excessive dieting, excessive exercising, purging and binging. According to Grieve (2007), the views of muscularity as the ideal body type for men are reinforced by family, significant others and friends. Social influence is a strong predictor of dietary behaviors (Huon, Lim, \& Gunewardene, 2000). Research has shown that members of particular social groups may exhibit the same behaviors as their peers in order to avoid being rejected (Shea \& Pritchard, 2007). If and when uniformity exists in social groups it can be implied that friends will tend to consume the same type of media. According to Tiggemann and Miller (2010), about $82.5 \%$ of adolescent females report knowing about websites focusing on appearance through their friends. Media influence in combination with the influence friends exert over disordered eating and exercise behaviors, may suggest that friends affect the consumption of media in the form of viewing pro-anorexia websites in pursuit of thinness and drive for muscularity.

Research has shown that media usage has increased the occurrence of disordered eating behaviors and attitudes (Carney \& Louw, 2006). Disordered eating and exercise behaviors have been thought to be a female trend, and in past research, males have been ignored. However, studies show that males are at risk of developing disordered eating behaviors as well (Weltzin et al., 2005). Increased exposure to male ideals creates an increased level of drive for thinness and is an important predictor of drive for muscularity in men (Leit et al., 2002). This influence has become even stronger as mass media expands to the realm of the World Wide Web and with the birth of pro-anorexia websites, media influences on body image, exercise behaviors and disordered eating has increased. Pro-anorexia websites are full of pictures of thin female models, muscular and thin male models, as well as letters or quotes encouraging the continuation of anorexia, which has been found to have harmful effects (Bardone-Cone \& Cass, 2007). The media is an important source of body ideals for both men and women (Grabe et al., 2008). However, friend influence over the viewership and use of pro-anorexia websites may add to the already harmful effects of viewing pro-anorexia websites alone. Due to the impact friends have on both men's and women's dieting, drive for thinness, excessive exercise and the desire to gain muscle mass (Agliata \& Tantleff-Dunn, 2004; Shomaker \& Furman, 2009), it may be possible that friends influence the purposes of media use. Thus, friends could influence each other to view pro-anorexia websites to continue or institute drive for thinness and drive for muscularity.

The primary purpose of the present study is to explore the relationships between pro-anorexia website viewing, drive for thinness in females, and drive for muscularity in males in the college student population. Literature suggests that pro-anorexia websites and friend influence over the viewership of the websites may affect men's drive for muscularity and women's drive for thinness (Bardone-Cone \& Cass, 2006). Therefore, we have decided to focus on drive for thinness in females and drive for muscularity in males. We will also compare the correlations between pro-anorexia website viewing and drive for thinness and drive for muscularity against the relationships between general website viewing and drive for thinness and drive for muscularity. Second, the present study will examine the influence of friends on the use of pro-anorexia websites as a means to aid in the pursuit of thinness in females and the drive for muscularity in males. Finally, it will examine whether pro-anorexia website viewership and friend influence over viewership of pro-anorexia websites predict drive for thinness and drive for muscularity. Overall, this study hopes to expand on the research of pro-anorexia websites and their effects on drive for thinness and muscularity among the collegiate population.

We propose four hypotheses. Hypothesis 1: Drive for thinness will correlate with more frequent viewing of pro-anorexia websites as well as with general website viewing in women. Hypothesis 2: Drive for muscularity will 
correlate with more frequent viewing of pro-anorexia websites as well as with more general website viewing in men. Hypothesis 3: The influence of friends over the viewership of pro-anorexia websites will correlate with the viewership of pro-anorexia websites in both men and women. Hypothesis 4: Pro-anorexia website viewership will be predictive of drive for thinness in women and drive for muscularity in men. In addition, friend influence to view those websites will also be predictive of drive for thinness in women and drive for muscularity in men.

\section{Method}

\section{Participants}

Approximately 300 introductory psychology students 18 years or older participated in this study. Participants ranged in age, gender and race. About $55.9 \%$ were female students and $39.5 \%$ were male students. The average age was $22.37(S D=6.25)$, with the oldest student being 55 years old and the youngest 18 years old. About $76.8 \%$ of students were Caucasian, 6.5\% Latino, 5.5\% Asian, 1.9\% African-American, 1.0\% Pacific Islander, 1.3\% Native Americans and $2.9 \%$ considered themselves as 'Other.' The Institutional Review Board approved the study protocol before data collection began.

\section{Materials and procedure}

Drive for thinness. Disordered eating symptoms were measured by the Drive for Thinness Subscale (DT) from the Eating Disorder Inventory (Garner \& Olmsted, 1984). The subscale is known to reliably distinguish individuals with symptoms of anorexia and those without symptoms of anorexia (Garner, Olmsted, \& Garfinkel, 1983). Participants respond to statements regarding extreme dieting, preoccupation with weight, and the fear of gaining weight (i.e., I thinking about dieting and I am preoccupied with the desire to be thinner) using a 6-point Likert Scale $(1=$ always, $2=$ usually, $3=$ often, $4=$ sometimes, $5=$ rarely and $6=$ never $)$. Items were summed to create a scale score $(\alpha=.92)$.

Drive for muscularity. Drive for muscularity was measured by the Drive for Muscularity Scale (DFM) (McCreary \& Sasse, 2000). The DFM questions were adapted to include questions about how they felt about body tone (i.e., I think I would feel more confident if I had more muscle mass/body tone). Responses were based on a 6point Likert scale $(1=$ always, $2=$ very often, $3=$ often, $4=$ sometimes, $5=$ rarely, and $6=$ never $)$. The DFM is scored by obtaining the average rating of the items, with higher scores indicating a greater drive for muscularity $(\alpha$ $=.91)$.

Pro-anorexia websites influence. Pro-anorexia websites influence questionnaire was adapted by the author from the Multidimensional Media Influence Scale (MMIS) (Cusumano \& Thompson, 2001). The MMIS questions were adapted to ask about pro-anorexia website viewership (i.e., I like to browse websites that support anorexia) and the motivations behind viewership of the websites (i.e., I like to browse websites that support anorexia in order to get motivated to lose weight). Responses were based on a 5-point Likert Scale (1=strongly agree, $2=$ agree, $3=$ neither agree nor disagree, $4=$ disagree and 5=strongly disagree $)$. Items were summed to create a scale score $(\alpha$ $=.79$ ).

General media influence. General media influence questionnaire was adapted by the author from the Multidimensional Media Influence Scale (MMIS) (Cusumano \& Thompson, 2001). The MMIS questions were adapted to ask about general website viewership (i.e., I like to browse websites that contain pictures of thin celebrities.) and the motivations behind viewership of the websites (i.e., I would like my body to look like the pictures of models). Responses were based on a 5-point Likert Scale (1=strongly agree, $2=$ agree, $3=$ neither agree nor disagree, $4=$ disagree and $5=$ strongly disagree $)$. Items were averaged to create a scale $(\alpha=.85)$.

Friend influence. Friend influence questionnaire was adapted from the Perceived Friend Preoccupation with Weight and Dieting Scale by Shroff (2005). The 9-item scale was adapted to ask questions more relevant to the encouragement of disordered eating behaviors and the viewership of pro-anorexia websites (i.e., How often do your friends: Encourage you to view websites that support anorexia). Responses were based on a 5-point Likert Scale ( $1=$ 
never, $2=$ rarely, $3=$ sometimes, $4=$ quite often and $5=$ very often $)$. Higher scores indicated a higher friend influence over viewership and drive for thinness $(\alpha=.88)$.

General friend influence. General friend influence questionnaire was adapted from the Perceived Friend Preoccupation with Weight and Dieting Scale by Shroff (2005). The 9-item scale was adapted to ask questions more relevant to the encouragement of disordered eating behaviors (i.e., How often do your friends: Encourage you to lose weight, Comment on each other's weight, and Talk about weight and dieting). Responses were based on a 5point Likert Scale $(1=$ never, $2=$ rarely, $3=$ sometimes, $4=$ quite often and $5=$ very often $)$. Items scores were averaged to create a scale $(\alpha=.84)$.

Undergraduate students were given the surveys individually through Qualtrics, an online survey software. Time limits to complete the survey were not set, thus an average time of completion was not recorded. Upon participation completion, each student was awarded credit points towards their General psychology class grade.

\section{Results}

\section{The relation between media, friend influence, and drive for muscularity in men}

As predicted, drive for muscularity was positively correlated with more frequent viewing of pro-anorexia websites (see Table 1). Drive for muscularity and general website viewing were also positively correlated (see Table 1). Drive for muscularity did not correlate with friend influence to view pro-anorexia websites, or with general friend influence (see Table 1)

\section{The relation between media, friend influence, and drive for thinness in women}

Our hypothesis that the drive for thinness would correlate with more frequent viewing of pro-anorexia websites was supported (see Table 2). Drive for thinness was positively correlated with general website viewing (see Table 2). Finally, drive for thinness was positively correlated with friend influence to view pro-anorexia websites as well as with general friend influence (see Table 2).

\section{Predicting drive for muscularity in men and drive for thinness in women}

In order to determine predictors for drive for muscularity in men and drive for thinness in women, we regressed the viewing of pro-anorexia websites, general websites, friend influence to view pro-anorexia websites and general friend influence on DFT and DFM using the stepwise method separately for men and women (see Table $3)$. Interestingly, the only predictor of drive for muscularity in men was viewership of pro-anorexia websites, $R^{2}=.10, F(1,116)=12.31, p=.001$ (see Table 3).

Similarly, pro-anorexia website viewership was the primary predictor of drive for thinness in women $R^{2}=$ $.30, F(1,161)=70.79, p<.001$, with general friend influence serving as the secondary predictor, $R^{2}=.39, F(2,160)$ $=50.87, p<.001$, and general website viewing as the tertiary predictor, $R^{2}=.41, F(3,159)=37.48, p<.001$ (see Table 3).

\section{Discussion}

We hypothesized that drive for thinness would correlate with more frequent viewing of pro-anorexia websites, as well as with general website viewing in women. We further hypothesized that drive for muscularity would correlate with more frequent viewing of pro-anorexia websites, as well as with more general website viewing in men. Both of these hypotheses were supported. In addition, we hypothesized that the influence of friends over the viewership of pro-anorexia websites would be related to the viewership of pro-anorexia websites in both men and women, which was also supported. We expected that pro-anorexia website viewership would be predictive of drive for thinness in women and muscularity in men. Lastly, we proposed that friend influence to view those websites would also be predictive of drive for thinness in women and drive for muscularity in men. Results were not quite as we predicted, as will be discussed below separately for men and women. 
Men

The results from the present study show a positive relationship between drive for muscularity and proanorexia website viewing in men. This is not surprising given the research suggesting that increased exposure to male ideals creates an increased level of drive for thinness and is an important predictor of drive for muscularity in men (Leit et al., 2002). Contrary to our hypothesis, we found that friend influence to view pro-anorexia websites did not correlate with the increase of drive for muscularity in men, nor did general friend influence. This is interesting given that Agliata and Tantleff-Dunn (2004) and Shomaker and Furman (2009) suggested friends have influence over the dieting, drive for thinness, excessive exercise and the desire to gain muscle mass in both men in women. Future research will need to explore this issue in more depth.

Additionally, the present showed that pro-anorexia website viewership was the only predictor of drive for muscularity in men. This is not surprising given previous research (Agliata \& Tantleff-Dunn, 2004; Baird \& Grieve, 2006; Derenne, 2006; Leit et al., 2002) that has consistently shown media, and in this case viewership of proanorexia websites, are a strong predictor for muscularity because of the portrayal of the male body ideal.

\section{Women}

The present study found that viewing and using pro-anorexia websites and general websites is predictive of drive for thinness in women. This is not surprising given Rodgers et al. (2010) finding that the influence of mass media is one contributor to increased drive for thinness. When it came to friend influence, we found a significant relationship between the influence to view pro-anorexia websites and drive for thinness, as well as general friend influence. Literature suggests that although media is indeed proving to be a strong influence on disordered eating and exercise behaviors, friend influence seems to still make its mark as a contributing factor. Corroborating research by Tiggemann and Miller (2010) found that a high percentage of girls reported friend influence on website viewing choices. The results from the present study are also in accordance with research suggesting that social influence is a factor in predicting dieting behaviors (Huon et al., 2000) and that close relationships (i.e., friends and family) influence the development of drive for thinness, excessive exercise and the desire to gain muscle mass (Shomaker \& Furman, 2009).

Additionally, the present study showed that pro-anorexia website viewership was a strong predictor of drive for thinness in women, followed by general friend influence and general website viewing. Research by BardoneCone and Cass (2006, 2007) and Carney and Louw (2006) has suggested that media has harmful effects on individuals and that it may increase the likelihood of developing disordered eating. The present study's results reveal that media may enhance drive for thinness in women. Homan (2010) suggested that the increased promotions of thin body ideals makes disordered eating behaviors harder to prevent. Results show that although in some instances the effect may be small, the relationship between media and existence of drive for thinness is still present. Therefore, it can be inferred that such body ideals in media, such as pro-anorexia websites, may impact the development of drive for thinness in women.

Overall, these findings suggest that women may be more susceptible to the influence of pro-anorexia websites than men. The results also showed that as friend influence to view pro-anorexia websites increases so does the viewership of pro-anorexia websites. Though the relationships were moderately correlated, especially in women, it gives us an insight into the influence friends have in the choices individuals make while in the college environment. Friends may still be significantly influencing the consumption and use of media in college students. However, it is important to note, friend influence to view pro-anorexia websites affects drive for thinness in women, but not drive for muscularity in men.

\section{Limitations}

The present study has several limitations that must be addressed. First, this study was correlational in nature; we cannot say whether viewership of pro-anorexia websites causes drive for thinness or drive for muscularity. Another limitation is that the results were based on self-report survey data, which does not ensure complete honesty from the participants. 


\section{Conclusion}

Our study shows that while drive for muscularity in men is correlated with the viewership of pro-anorexia websites, drive for thinness in women has a stronger relationship with the viewership of pro-anorexia websites. Friend influence to view pro-anorexia websites is correlated with the viewership of pro-anorexia websites; however friend influences to view pro-anorexia websites only related to drive for thinness and not drive for muscularity. Lastly, pro-anorexia websites viewership is a strong predictor of drive for thinness in women and the only predictor of drive for muscularity in men.

All in all we believe the findings in this study will aid in the expansion of knowledge of pro-anorexia websites. Understanding what factors may lead to the development of disordered eating and exercise behaviors, specifically drive for muscularity and thinness, will allow for greater treatment methods and effectiveness. Knowledge in this area will also help address the increasing threat of the online realm on body image issues. Overall awareness of the effects of viewing pro- anorexia websites will help the greater population educate individuals on the harmful effects of these websites. Future research should examine how pro-anorexia websites affect the development of disordered eating, as well as the eating disorders anorexia and bulimia.

\section{Acknowledgements}

The author wishes to express her appreciation to Dr. Mary Pritchard for all the support and guidance, to Dr. Kimberly Henderson and Dr. Teresa Taylor, to my fellow McNair Scholars, especially to Lori Henderson, to the McNair program (Helen, Diana and Greg), to my research partner, Ernesto Soto. To my lovely family and my parents to whom I owe all that I am. To Edward Kim, my husband, who has supported me in everything that I do.

Table 1. Correlations Between Friend and Media influence and Drive for Muscularity in Men

\begin{tabular}{lllllll}
\hline \multirow{2}{*}{ Measure } & Men & & & & & \\
\cline { 2 - 7 } & Mean (SD) & 1 & 2 & 3 & 4 & 5 \\
\hline 1.Drive for muscularity & $3.70(.93)$ & -- & $-.31^{* *}$ & $-.31^{* *}$ & .04 & -.10 \\
2. Pro-anorexia website use & $1.75(.64)$ & & -- & $.73^{* *}$ & $.25^{* *}$ & $.35^{*}$ \\
3.General website viewing & & & & - & .11 & $.29^{*}$ \\
$\begin{array}{l}\text { 4. Friend influence over pro-anorexia } \\
\text { websites. }\end{array}$ & $1.31(.65)$ & & & & \\
5. General friend influence & & & & & & $.57^{* *}$
\end{tabular}

Note. ${ }^{*} p<.001,{ }^{* *} p<.05$

Note. $\mathrm{CI}=$ confidence interval 
Table 2. Correlations Between Friend and Media influence and Drive for Thinness in Women

\begin{tabular}{lllllll}
\hline \multirow{2}{*}{ Measure } & Women & & & & & \\
\cline { 2 - 7 } & Mean (SD) & 1 & 2 & 3 & 4 & 5 \\
\hline 1. Drive for thinness & $21.10(8.4)$ & -- & $.57^{*}$ & $.54^{*}$ & $.26^{*}$ & $.51^{*}$ \\
2. Pro-anorexia website use & $2.33(.76)$ & & -- & $.77^{*}$ & $.40^{*}$ & $.47^{*}$ \\
3. General website viewing & & & & & \\
4. Friend Influence over pro-anorexia & & & & & $.24^{* *}$ & $.44^{*}$ \\
websites. & $1.30(.59)$ & & & & & \\
5. General friend influence & & & & & & $.52^{*}$
\end{tabular}

Note. ${ }^{*} p<.001,{ }^{* *} p<.05$

Note. $\mathrm{CI}=$ confidence interval

Table 3. Predictors of Drive for Thinness in Women and Drive for Muscularity in Men

\begin{tabular}{|c|c|c|c|c|c|c|}
\hline \multirow{2}{*}{ Variable } & \multicolumn{3}{|c|}{ Women } & \multicolumn{3}{|l|}{ Men } \\
\hline & B & SE B & $\beta$ & B & SE B & $\beta$ \\
\hline Step 1 & & & & & & \\
\hline $\begin{array}{l}\text { Pro-anorexia } \\
\text { websites }\end{array}$ & 6.14 & .73 & $.55^{* *}$ & -.45 & .13 & $-.31 * *$ \\
\hline \multicolumn{7}{|l|}{ Step 2} \\
\hline $\begin{array}{l}\text { Pro-anorexia } \\
\text { websites }\end{array}$ & 4.30 & .80 & $.40^{* *}$ & -- & -- & -- \\
\hline $\begin{array}{l}\text { General friend } \\
\text { influence }\end{array}$ & 3.50 & .75 & $.33 * *$ & -- & -- & -- \\
\hline \multicolumn{7}{|l|}{ Step 3} \\
\hline $\begin{array}{l}\text { Pro-anorexia } \\
\text { websites }\end{array}$ & 2.16 & 1.1 & .19 & -- & -- & -- \\
\hline $\begin{array}{l}\text { General friend } \\
\text { influence }\end{array}$ & 3.30 & .74 & $.31^{* *}$ & -- & -- & -- \\
\hline $\begin{array}{l}\text { General media } \\
\text { influence }\end{array}$ & 2.11 & .80 & $.26^{*}$ & -- & -- & -- \\
\hline
\end{tabular}




\section{References}

[1] Agliata, D., \& Tantleff-Dunn, S. (2004). The impact of media exposure on males' body image. Journal of Social and Clinical Psychology, 23, 7-22.

[2] Alperin, R. (2005). Young children and disturbed eating attitudes and behaviors: Relationships with parents, peers, media, and body image. Dissertation Abstracts International, 65, Retrieved from PsycINFO database.

[3] American Psychiatric Association., \& American Psychiatric Association. (2000). Diagnostic and statistical manual of mental disorders: DSM-IV-TR. Washington, DC: American Psychiatric Association.

[4] Bardone-Cone, A., \& Cass, K. (2006). Investigating the impact of pro-anorexia websites: a pilot study. European Eating Disorders Review, 14, 256-262.

[5] Bardone-Cone, A. M., \& Cass, K. M. (2007). What does viewing a pro-anorexia website do? An experimental examination of website exposure and moderating effects. International Journal of Eating Disorders, 40, 537-548.

[6] Baird, A., \& Grieve, F. (2006). Exposure to Male Models in Advertisements Leads to a Decrease in Men's Body Satisfaction. North American Journal of Psychology, 8(1), 115-121

[7] Carney, T., \& Louw, J. (2006). Eating disordered behaviors and media exposure. Social Psychiatry \& Psychiatric Epidemiology, 41, 957-966.

[8] Cook-Cottone, C. P., \& Phelps, L. (2006). Adolescent eating disorders. In G. Bear, K. Minke, and A. Thomas (Eds.), Children's needs III: Understanding and addressing. The developmental needs of children (pp. 977988). Bethesda, MD: National Association of School Psychologists Publications.

[9] Cusumano, D. L., \& Thompson, J. K. (2001). Media influence and body image in 8-11-year-old boys and girls: A preliminary report on the multidimensional media influence scale, International Journal of Eating Disorders 29, 37-44.

[10] Derenne, Jennifer L. (05/01/2006). Body image, media, and eating disorders. Academic Psychiatry (10429670), 30, p. 257.

[11] Fairburn, C. G., \& Bohn, K. (2005). Eating disorder NOS(EDNOS): An example of the troublesome "not otherwise specified" (NOS) category in DSM-V. Behaviour Research and Therapy, 43,691-701.

[12] Fairburn, C.G., Cooper, Z., Bohn, K., O’Connor, M.E., Doll, H.A., Palmer, R.L. (2007). The severity and status of eating disorder NOS: Implications for DSM-V. Behaviour Research and Therapy, 45, 1705-1715.

[13] Garner, D., M., \& Olmsted, M. P. (1984). Manual for Eating Disorder Inventory. Odessa, FL: Psychological Assessment Resources, Inc.

[14] Garner, D., Olmsted, M., \& Garfinkel, P. (1983). Does Anorexia Nervosa occur on a continuum: Subgroups of weight-preoccupied women and their relationship to Anorexia Nervosa. International Journal of Eating Disorders, 2, 11-20.

[15] Grabe, S., Ward, L., \& Hyde, J. (2008). The role of the media in body image concerns among women: A metaanalysis of experimental and correlational studies. Psychological Bulletin, 134, 460-476.

[16] Grieve, F. G. (2007). A conceptual model of factors contributing to the development of muscle dysmorphia. Eating Disorders, 15, 63-80.

[17] Homan, K. (2010). Athletic-ideal and thin-ideal internalization as prospective predictors of body dissatisfaction, dieting, and compulsive exercise. Body Image, 7, 240-245.

[18] Huon, G., Lim, J., \& Gunewardene, A. (2000). Social influences and female adolescent dieting. Journal of Adolescence, 23, 229-232.

[19] Kjelsås, E., Bjørnstrøm, C., \& Götestam, K. (2004). Prevalence of eating disorders in female and male adolescents (14-15 years). Eating Behaviors, 5, 13-25.

[20] Leit, R., Gray, J., \& Pope, H. (2002). The media's representation of the ideal male body: A cause for muscle dysmorphia? International Journal of Eating Disorders, 31(3), 334-338.

[21] McCreary, D. R., \& Sasse, D. K. (2000). An exploration of the drive for muscularity in adolescent boys and girls. Journal of American College Health, 48, 297-304.

[22] Murray, S. B., Rieger, E., Touyz, S. W., \& De la Garza García, Y. (2010). Muscle dysmorphia and the DSM-V conundrum: Where does it belong? A review paper. International Journal of Eating Disorders, 43, 483-491

[23] O'Dea, J., \& Abraham, S. (2002). Eating and exercise disorders in young college men. Journal of American College Health, 50, 273.

[24] Ridgeway, R.T., \& Tylka, T.L. (2005). College men's perceptions of ideal body composition and shape. Psychology of Men and Masculinity, 6, 209-220. 
[25] Rodgers, R., Paxton, S., \& Chabrol, H. (2010). Depression as a moderator of sociocultural influences on eating disorder symptoms in adolescent females and males. Journal of Youth and Adolescence, 39, 393-402.

[26] Shea, M., \& Pritchard, M. (2007). Is self-esteem the primary predictor of disordered eating? Personality and Individual Differences, 42, 1527-1537.

[27] Shomaker, L., \& Furman, W. (2009). Interpersonal influences on late adolescent girls' and boys' disordered eating. Eating Behaviors, 10, 97-106.

[28] Shroff, H. (2005). An examination of peer related risk and protective factors for body image disturbance and disordered eating in adolescent girls. Dissertation Abstracts International, 65, Retrieved from PsycINFO database.

[29] Tamim, H., Tamim, R., Almawi, W., Rahi, A., Shamseddeen, W., Ghazi, A., et al. (2006). Risky weight control among university students. International Journal of Eating Disorders, 39, 80-83.

[30] Tiggemann, M., \& Miller, J. (2010). The Internet and adolescent girls' weight satisfaction and drive for thinness. Sex Roles, 63, 79-90.

[31] Wang, S., Houshyar, S., \& Prinstein, M. (2006). Adolescent girls' and boys' weight-related health behaviors and cognitions: Associations with reputation- and preference-based peer status. Health Psychology, 25, 658663.

[32] Weltzin, T., Weisensel, N., Franczyk, D., Burnett, K., Klitz, C., \& Bean, P. (2005). Eating disorders in men: Update. Journal of Men's Health \& Gender, 2, 186-193.

[33] Williams, S., \& Reid, M. (2007). A grounded theory approach to the phenomenon of pro-anorexia. Addiction Research \& Theory, 15, 141-1521 (1), 3-25. 